\title{
Inovação Social para o Desenvolvimento Sustentável: um caminho possível
}

Social Innovation for Sustainable Development: a possible way

Innovación Social para el Desarrollo Sostenible: un camino posible

Suzanne Érica Nóbrega Correia Doutorado em Administração pela Universidade Federal de Pernambuco Professora Adjunto da Universidade Federal de Campina Grande http://lattes.cnpq.br/0431849242809370 https://orcid org/0000-0003-3613-234X suzanne.enc@gmail.com

Verônica Macário de Oliveira Doutorado em Administração pela Universidade Federal de Pernambuco Professora Adjunto da Universidade Federal de Campina Grande http://lattes.cnpq.br/5942955873045875 veronicamacario@gmail.com

Maria José da Silva Feitosa Doutoranda em Administração (Concentração em Política e Gestão Públicas) pela Universidade Federal do Rio Grande do Norte - PPGA/UFRN Professora Assistente do Curso de Administração da Universidade Federal Rural de Pernambuco, Unidade Acadêmica de Serra Talhada - UFRPE/UAST. http://lattes.cnpq.br/6887857776351323 mjsfeitosa@gmail.com

Carla Regina Pasa Goméz Doutorado em Engenharia de Produção pela Universidade Federal do Rio Grande do Su Professora Associada da Universidade Federal de Pernambuco http://lattes.cnpq.br/1964176230213353 carlapasagomez@gmail.com

Resumo: Este artigo tem como objetivo analisar como iniciativas de inovação social promovidas pelo Centro de Educação Comunitária Rural se relacionam com a promoção do desenvolvimento sustentável, através da aplicação do modelo de Mehmood e Parra (2013). Para tanto, realizou-se um estudo de caso descritivo e exploratório. Os resultados apontam que, na vulnerabilidade social, as necessidades sociais são sanadas pelo fortalecimento da sociedade civil através da articulação dos agricultores em forma de associações e à diminuição do assistencialismo governamental; quanto à viabilidade econômica, a iniciativa investigada proporciona melhoria significativa na renda familiar possibilitando sua participação em representações sociais e em feiras agroecológicas; na sustentabilidade ambiental, os resultados demonstraram melhoria na qualidade alimentar dos agricultores e o despertar seus interesses para práticas ambientais. Dessa forma conclui-se que as características da inovação social desenvolvidas pelo CECOR estão relacionadas com a promoção do desenvolvimento sustentável no níve local.

Palavras-chaves: Inovação Social; Desenvolvimento Sustentável; Transformação Social; Tecnologia Social.
Abstract: This article aims to analyze how socia innovation initiatives promoted by the Rural Community Education Center relate to the promotion of sustainable development through the application of the Mehmood and Parra's model (2013). Therefore, we used descriptive and exploratory study case. The results show that in social vulnerability, social needs are healed by the strengthening of civil society through the articulation of farmers to form associations and decreasing government welfare; regarding the economic viability, the initiative investigated provides significan improvement in family income enabling their participation in social representations and agroecology fairs; in environmental sustainability, the results demonstrated an improvement in the food quality of farmers and the awakening of their interests to environmental practices. Thus, it is concluded that the characteristics of social innovation developed by CECOR are related to the promotion of sustainable development at the local level.

Keywords: Social Innovation; Sustainable development Social transformation; Social technology.
Resumen: Este artículo tiene como objetivo analizar cómo iniciativas de innovación social promovidas por el Centro de Educación Comunitaria Rural se relacionan con la promoción del desarrollo sostenible, a través de la aplicación del modelo de Mehmood y Parra (2013). Para ello, se realizó un estudio de caso descriptivo y exploratorio. Los resultados apuntan que, en la vulnerabilidad social, las necesidades sociales son sanadas por el fortalecimiento de la sociedad civil a través de la articulación de los agricultores en forma de asociaciones y la disminución del asistencialismo gubernamental; en cuanto a la viabilidad económica, la iniciativa investigada proporciona una mejora significativa en la renta familiar posibilitando su participación en representaciones sociales y en ferias agroecológicas; en la sostenibilidad ambiental, los resultados demostraron una mejora en la calidad alimentaria de los agricultores y el despertar sus intereses para las prácticas ambientales. De esta forma, se concluye que las características de la innovación social desarrolladas por el CECOR están relacionadas con la promoción del desarrollo sostenible a nivel local. Palabras claves: Innovación Social; Desenvolvimiento sustentable; Transformación Social; Tecnología Social.

Texto completo em português: http://www.apgs.ufv.br Full text in Portuguese: http://www.apgs.ufv.b

\section{Introdução}

Ao longo das últimas décadas, diversos movimentos sociais concentraram suas atenções para os desafios da globalização e a necessidade de se promover o desenvolvimento sustentável (Michel \& Hundon, 2015). As preocupações remetem principalmente à obsessão pelo crescimento econômico como principal filosofia do desenvolvimento (Seyfang \& Longhurst, 2013), o que resulta na ampliação das disparidades sociais e no declínio das economias locais (Strange \& Bayley, 2008), além de se promover o esgotamento dos recursos naturais e a degradação do meio ambiente (Jackson \& Senker, 2011).
Nesse contexto, uma das questões principais, que circunda 0 desenvolvimento sustentável, está relacionada à superação do paradigma desenvolvimentista unilateral que concentra suas ações em prol do crescimento econômico por um desenvolvimento endógeno, no qual a comunidade se insere em práticas democráticas e participativas, capazes de alavancar o bem estar, as condições de vida e aumentar a renda da população, bem como melhorar e preservar as condições ambientais do seu entorno.

O Relatório de Brundtland trouxe à tona a necessidade de se integrar a proteção ambiental ao desenvolvimento econômico e à justiça social como um pacto geracional. Assim, a proposta de valor do desenvolvimento

Correspondência/Correspondence: Suzanne Érica Nóbrega Correia. Universidade Federal de Campina Grande, Centro de Humanidades, Unidade Acadêmica de Administração e Contabilidade (UAAC). Av. Aprígio Veloso, 882, Bairro Universitário. 58.429-900. Campina Grande, Paraíba, Brasil. suzanne.enc@gmail.com 
integrado busca satisfazer a necessidade de gerar simetria e equilibrar as perspectivas do crescimento econômico, da preservação do meio ambiente (sustentabilidade) e da justiça social (equidade) (Koroneos \& Rokos, 2012).

É inegável que o crescimento econômico é condição necessária, mas não suficiente, para promover o desenvolvimento (Sachs; 2007). Considera-se que só haverá verdadeiro desenvolvimento em localidades onde existirem um projeto social subjacente. Assim, a dimensão social do desenvolvimento se adere à integração da economia com vistas a garantir o impacto das atividades atuais sobre as gerações futuras, principalmente por reconhecer que o bem-estar humano é construído além da melhoria e crescimento da renda. E por fim, não menos desconecta está relacionada aos objetivos de preservação e conservação do meio ambiente, considerados fundamentais ao benefício de gerações futuras (Sepúlveda, 2008; Keeys \& Huemann, 2017).

Nessa direção assume-se que o desenvolvimento sustentável exige 0 envolvimento de todos os stakeholders da sociedade (Koroneos \& Rokos, 2012) para sua efetivação. Caracteriza-se como um processo de construção social que incita a participação da sociedade civil para trocar experiências, mudar comportamentos e gerar soluções na busca de um caminho com condições de vida mais dignas para a sociedade atual e futura. O ponto de partida é o reconhecimento dos desafios que permeiam esse processo e a necessidade de desenvolver soluções e buscar investimentos capazes de promover essa mudança social.

Surge, então, a inovação social, entendida como um processo de transformação nos padrões de resposta às necessidades sociais profundas, através da ruptura com as normas vigentes, com os valores instituídos e com a estrutura da distribuição de poder e recursos (Correia, Oliveira, \& Gomez, 2016). Isto é, a inovação social surge como uma iniciativa que escapa à ordem estabelecida, implicando, pois, em uma mudança clara, criativa e significativa, na forma como uma sociedade lida com um determinado problema social complexo, anteriormente sem respostas contundentes, como a pobreza, a violência ou a deterioração ambiental (Nilsson, 2003)

Diante disso, o conceito de inovação social aparece como uma premissa para a construção de um novo modelo de atendimento às demandas sociais com respeito à diversidade e à unidade humana, e que contribua para a promoção da igualdade na sociedade pós-moderna (Farfus \& Rocha, 2007).

Reconhecendo tais características da inovação social é que esse trabalho parte do pressuposto de que as iniciativas de inovação social ajudam a compreender e materializar ações coletivas que buscam promover o desenvolvimento sustentável de localidades, de modo que ele será o resultado das inovações sociais geradas, implementadas e difundidas a partir das necessidades sociais específicas do contexto. Portanto, torna-se necessário investigar as relações estabelecidas entre as iniciativas de inovação social como mecanismos de promoção do desenvolvimento sustentável.

Apesar de existirem outras iniciativas políticas, econômicas e institucionais que são importantes para a promoção do desenvolvimento sustentável, considera-se que o fortalecimento da participação da sociedade civil, a partir de iniciativas de inovação social, seja um elemento imprescindível neste processo, sob a perspectiva de uma gestão democrática e participativa que, de fato, considere as necessidades das localidades onde as ações serão implementadas.

Assim, este artigo objetiva analisar como as iniciativas de inovação social (IS) promovidas pelo Centro de Educação Comunitária Rural (CECOR - PE), em seus programas de Cisternas (P1MC e P1+2), se relacionam com a promoção do desenvolvimento sustentável (DS). Para tanto, foi utilizado o modelo de Mehmood \& Parra (2013), que se propõe a mapear as conexões que buscam vincular as características fundamentais da inovação social (satisfação das necessidades humanas, mudança nas relações sociais, capacidade sociopolítica; e governança) com as dimensões do desenvolvimento sustentável (vulnerabilidade social, sustentabilidade ambiental e viabilidade econômica). Metodologicamente, realizou-se um estudo de caso descritivo e exploratório, com realização de entrevistas semiestruturadas junto a gestores do programa supracitado.

\section{Desenvolvimento sustentável: aspectos conceituais e críticas}

Modelos desenvolvimentistas relacionados à sustentabilidade romperam com a dicotomia entre o crescimento e desenvolvimento já apregoado por Sachs nos anos 80. Apesar do crescimento econômico ainda se apresentar como um dos desafios centrais a ser enfrentado pelas sociedades contemporâneas, a promoção do desenvolvimento busca agregar outros valores, além da dinâmica econômica para a estruturação de políticas de desenvolvimento (Michael \& Hudon, 2015), as quais sejam capazes de promover o equilíbrio ambiental e a justiça social.

É nesse sentido que 0 desenvolvimento sustentável rompe com as análises puramente econômicas trazendo ao debate aspectos qualitativos que envolvem a capacidade dos indivíduos em gerar esforços, e individuais e conjuntos para atender as necessidades sociais das localidades (Furtado, 2004; Veiga, 2005, Dietz \& O’Neill, 2013), o que vai ao encontro da proposição de Sachs (1986) para o conceito de ecodesenvolvimento, cujo sistema é endógeno, de modo que cada região fornece soluções específicas para seus problemas particulares, apresentando-se como uma reação às soluções generalistas e universais apresentadas de modo convencional como alternativas às demandas sociais da sociedade.

Historicamente, a proposta de desenvolvimento sustentável vem se moldando aos debates internacionais e aportando discussões que perpassam a reparação das desigualdades sociais existentes e melhoria das condições de vida das pessoas (Sachs, 2004), buscando articular os objetivos econômicos, sociais e ambientais da sociedade de forma equilibrada (WCED, 1987). Sua ideia tem sido construída a partir de distintas perspectivas, em contraponto à visão tradicional de crescimento herdada do século XIX, que privilegia o crescimento econômico e a industrialização como sinônimos de desenvolvimento, desconsiderando o caráter finito dos recursos naturais (Sachs, 2007; Beck, 2011).

Não existe uma única interpretação sobre o termo "desenvolvimento sustentável" (DS), visto que o referido é um conceito ainda em construção, constantemente revisado e aperfeiçoado (Soubbotina, 2004; Karampela, Papazoglou, Kizos, \& Spilanis, 2017). Corroborando este entendimento, Van Bellen (2004) destaca que, apesar de ser um termo intensamente empregado, não existe consenso a seu respeito e, portanto, há significativa variedade conceitual nas discussões que o envolvem. Contudo, de acordo com o World Wildlife Fund - (WWF Brasil, 2015), a definição mais aceita sobre o termo consta no Relatório de Brundtland, proposto pela Comissão 
Mundial sobre Meio Ambiente e Desenvolvimento (CMMAD), em 1987, que estabelece que desenvolvimento sustentável é aquele capaz de suprir as necessidades da geração atual, sem comprometer a capacidade de atender as necessidades das futuras gerações.

Ainda, questiona-se também a viabilidade desse modelo, embasado no fato de que não se pode haver um "desenvolvimento sustentável" global em uma economia mundial industrializada, que permaneça fortemente dependente da extração do estoque finito de recursos naturais não renováveis (Arivumani \& Vijayalaxmi, 2017). Além disso, do ponto de vista teórico, o amplo apelo e a institucionalização do desenvolvimento sustentável carecem ainda de elementos que sejam capazes de alterar o comportamento de atores-chave, que podem produzir ações coordenadas de alto impacto (Hadden \& Seybert, 2016) e promover as mudanças necessárias. Ademais, algumas críticas recaem sobre a sua ambiguidade e amplitude da proposta (Riordan, 1995; Veiga, 2005, Mitchell \& Dorling, 2003), por ser entendida como opção deliberada de uma estratégia de institucionalização da problemática ambiental no âmbito das organizações internacionais e dos governos nacionais (Veiga, 2005).

O que se convencionou e é unânime é que as definições de desenvolvimento sustentável incorporam a ideia de três pilares interdependentes que compreendem três grandes objetivos: 1) a erradicação da pobreza; 2) a mudança dos padrões de produção e consumo e; 3 ) a proteção e o manejo da base de recursos naturais para 0 desenvolvimento econômico e social (Sachs, 2007; Veiga, 2005). Isto remete a necessidade de se alcançar o equilíbrio em termos de proteção ambiental, igualdade social e crescimento econômico como base das ações do desenvolvimento sustentável (Pronk \& Hak, 1992; Sachs, 2007; Veiga, 2005), dentro de uma perspectiva multidimensional que inclui as dimensões: social, econômico e ambiental.

A dimensão social se refere a construção de uma sociedade mais justa, através da redução das desigualdades sociais que devem ser refletidas na erradicação da pobreza e redução das disparidades regionais; promoção da saúde e proteção dos grupos socialmente vulneráveis; educação como um instrumento fundamental da mudança; desenvolvimento de políticas públicas de caráter social; e respeito por padrões culturais (Sachs, 2015). A dimensão econômica está relacionada com a capacidade e o potencial econômico das regiões e microrregiões de construir em cada etapa da produção e distribuição ativos relevantes e úteis para indivíduos, comunidades e territórios com os quais as empresas responsáveis por esta criação se relacionam (Abramovay, 2012). Finalmente, a dimensão ambiental envolve um novo padrão de produção e consumo que ajuda a promover a gestão sustentável dos recursos naturais, incluindo a manutenção da biodiversidade, a estabilidade atmosférica e outras funções do ecossistema, que normalmente não são classificadas como recursos econômicos (Harris, 2000; Abramovay, 2012).

As referidas dimensões abordam explicitamente mudanças que vão muito além de inovações técnicas, isto é, que exigem a necessidade de um plano multidimensional de ação que incide sobre inovações sociais necessárias às junções entre diferentes racionalidades, com o objetivo de encontrar as melhores formas e alternativas para atender às necessidades sociais existentes (Howaldt \& Schwarz, 2010).

As soluções para os problemas sociais e ecológicos não estão nas forças de mercado, mas nas inovações sociais que podem contribuir para a superação das crises provocadas pelo crescimento econômico (Sachs, 2015; Arámburo, González, \& Rivas, 2017). Em outras palavras, a inovação social (IS) pode ser uma alternativa para responder às múltiplas crises ambientais, sociais e econômicas enfrentadas pelas sociedades em todo 0 mundo (Pisano, Lange, \& Berger, 2015). Nesse sentido, Fachinelli, D'arisbo e Maciel (2014, p. 276) ressaltam que a IS pode transformar a realidade "através de um processo coletivo de criação, aprendizagem e invenção que estabelece novas práticas sociais sustentáveis".

Assim, paralelamente à amplitude e importância do tema desenvolvimento sustentável, a geração de inovações sociais, conforme Caron (2007), pode ser considerada essencial por desenvolver espaços locais e segmentos sociais marginalizados, bem como inseri-los no processo de desenvolvimento econômico, social e ambiental.

\section{A emergência da inovação social}

Nos últimos dez anos, estudos sobre inovação social tem surgido em diferentes contextos, tornando o conceito amplo e complexo. Um pensamento socialmente inovador tem tomado muitas formas decorrentes do trabalho inspirador dos indivíduos ou grupos de investigação sobre inovação social, apresentando assim, uma série de teorias e projetos que podem responder a soluções aos problemas sociais que enfrenta a nível local, nacional ou internacional.

No entanto, os limites dos processos de inovação social ainda não foram completamente definidos, apresentando-se em diversos contextos, e deixando um espaço para contribuições teóricas e empíricas (CajaibaSantana, 2013; Van Der Have \& Rubalcaba, 2016). Inovação social apresenta-se como uma solução eficaz, eficiente e sustentável para um problema social, gerando maior valor que as práticas existentes, e seus benefícios alcançando toda a sociedade (Phills Jr., Deigmeier, \& Miller, 2008).

O CRISES (Centre de Recherche sur les Innovations Sociales) defendem que as inovações sociais promovem o bem-estar dos indivíduos e das comunidades, sendo caracterizado por um processo de implementação que envolva a cooperação entre uma variedade de atores e com o objetivo de se alcançar, a longo prazo, uma mudança social, podendo contribuir para o surgimento de um novo modelo de desenvolvimento (Cloutier, 2003; Tardif \& Harrisson, 2005).

Outra definição de inovação social pode ter foco nas novas ideias que funcionam para o cumprimento de objetivos sociais. Nesse contexto, define-se inovação social como atividades e serviços inovadores motivados pelo objetivo de atender a uma necessidade social e que são predominantemente desenvolvidas e difundidas por meio de organizações cujos objetivos principais são o social (Mulgan, Tucker, Ali \& Sanders, 2007). De acordo com esse conceito, as inovações sociais são vistas como elementos híbridos que atendem a novas formas existentes, transferindo ideias e novos limites das relações, desfrutando conhecimento cada vez maior em estudos sobre inovação.

Procurando sintetizar a inovação social, The Young Fundation apresenta um conceito normativo e analítico na formação e análise de soluções para problemas de exclusão social e no desenvolvimento de novas estratégias de integração social (Gerometta; Häussermann \& Longo, 2005) e que pode ser traduzido em três dimensões fundamentais (Moulaert, Martinelli, Swyngedouw \& Gonzalez, 2005), a saber: a) satisfação das 
necessidades humanas não satisfeitas, ou porque "ainda não", ou porque "não mais", é percebida como importante pelo mercado ou pelo Estado (Dimensão conteúdo); b) alteração nas relações sociais, especialmente no que se diz respeito a governança, aumentando o nível de participação de todos, em especial, os grupos desfavorecidos da sociedade (Dimensão processo); c) aumento da capacidade sócio-política e acesso aos recursos necessários para reforçar os direitos para satisfação das necessidades e participação dos indivíduos (Dimensão empoderamento).

Moulaert (2013) complementa que a inovação social pode ser compreendida como a inovação nas relações sociais dentro de micro e macro esferas, com o objetivo de satisfazer ou não necessidades humanas em diferentes camadas da sociedade.

Mesmo não havendo um consenso sobre a definição de inovação social (Goldenberg, Kamoji, Orton \& Williamson, 2009), há algo fundamental nessas definições. A inovação social representa uma resposta a um claro problema ou necessidade social, representam um valor compartilhado, fruto de uma colaboração entre diversos atores, atividades interpessoais ou interações sociais para atender a um ou mais objetivos comuns.

Dentro dos aspectos referentes a implementação de inovações sociais, existem três abordagens principais que são usadas para simular o seu desenvolvimento: atores externos que facilitam o desenvolvimento da inovação social (abordagem top-down); os atores locais que desenvolvem a inovação social (abordagem buttom-up); e os atores externos que facilitam uma capacidade institucional local a mobilizar seus recursos internos e desenvolver inovações sociais (abordagem em que a iniciativa top-down facilita a atividade buttom-up); no entanto, a perspectiva buttomup é mais eficiente quando implementadas em nível de comunidades, pela convivência diária com o problema social (Butkeviciene, 2009; Martin, Upham, \& Budd, 2015).

Dessa forma, pressupõe-se que um conjunto de inovações sociais devem ser adotadas pela sociedade civil através do desenvolvimento de habilidades específicas, que possibilitem 0 aproveitamento das potencialidades locais para a construção desse novo modelo de desenvolvimento (BEPA, 2011; Nicholls \& Murdock, 2012). Dessa forma, a sociedade civil tem um papel principal como agente das transformações sociais, política e econômicas, sendo incentivada a adotar medidas dentro de suas localidades que possam promover o desenvolvimento sustentável (Herrera, 2016). Uma sociedade organizada socialmente fortalece suas relações com outros agentes, a exemplo do governo, do mercado e das entidades sem fins lucrativos, geram relações de confiança e mantém os indivíduos unidos para promover ações coletivas.

A inovação social é estritamente ligada ao processo em que as organizações da sociedade civil e os movimentos sociais tornam-se gradualmente mais conscientes dos seus espaços e influências como importantes agentes na elaboração, implementação e prestação do serviço e bem-estar público (Hulgardi \& Ferrarini, 2010; Bittencour \& Ronconi, 2016). Assim, é possível afirmar que a sociedade civil é um setor que tem contribuído para o fortalecimento de iniciativas de inovação social (Correia, Oliveira, \& Gomez, 2016). Relacionada a esse contexto, as inovações sociais emergem como fator de renovação dos serviços de bem-estar e na contribuição para a mudança social, estando relacionada às estruturas democráticas e participativas de governo.
Dessa forma, inovações sociais passam a desempenhar um papel importante no contexto do desenvolvimento, buscando, através de suas iniciativas, oportunidades internas que favoreçam o desenvolvimento sustentável. Logo, o desenvolvimento sustentável poderá ser o resultado das inovações sociais geradas, implementadas e difundidas nas localidades, a partir das necessidades sociais específicas do contexto gerando ganhos ou respostas sociais. Desse modo, o processo de desenvolvimento sustentável pressupõe um conjunto de inovações sociais que devem ser adotadas pela sociedade civil através do desenvolvimento de habilidades específicas, que possibilitam 0 aproveitamento das potencialidades locais para a construção desse novo modelo de desenvolvimento.

\subsection{Inovação Social para o Desenvolvimento Sustentável}

A perspectiva da inovação social para o desenvolvimento sustentável pode ajudar a superar a desconexão entre crescimento econômico e bemestar social. Conforme já abordado anteriormente, a inovação social se refere à forma como os indivíduos, grupos e comunidades se mobilizam para enfrentar os problemas atendidos, e tem fortes conotações em termos de esforços sociais e institucionais para implementar os caminhos da sustentabilidade (Jaeger-Erben, Rückert-John, \& Schäfer, 2015). Desta forma, as políticas e as ações voltadas ao desenvolvimento sustentável podem ser potencializadas através da operacionalização de inovações sociais (Mehmood \& Parra, 2013).

Considera-se que o desenvolvimento de uma localidade deve privilegiar o atendimento das necessidades básicas da sua população e oferecer oportunidades de melhoria na sua qualidade de vida. As inovações sociais são consideradas um fator de mudança que pode atender este propósito ao buscar oferecer uma estrutura baseada em oportunidades, que considerem 0 atendimento daquelas necessidades e respeito aos valores humanos (Dearing, 2000; Herrera, 2016; Correia, Oliveira, Gomez, 2016).

Neste contexto, a inovação social possui três características fundamentais (Mehmood \& Parra, 2013), a saber: 1) a satisfação das necessidades humanas (tanto materiais e imateriais), incluindo as relacionadas com a melhoria da qualidade do ambiente, a inovação nas relações sociais, governança, empoderamento e justiça social - que reflete em um melhor índice de sustentabilidade; 2) relações sociais entre indivíduos e grupos em diferentes escalas espaciais, destacando questões locais; 3) empowerment, com iniciativas a nível micro, trazendo mudanças positivas ao nível macro. Entre as características abordadas, a escala espacial tem um papel importante no surgimento e eficácia das ações socialmente inovadoras, especialmente em termos do nível de intervenção da localidade e que tem como propósito o desenvolvimento local sustentável (Mehmood \& Parra, 2013).

Assim, para que um programa de inovação social cumpra seu papel no desenvolvimento sustentável, é necessário abordar três aspectos: i) deve existir 0 atendimento às especificidades locais, enquanto se busca simultaneamente a difusão e influência em larga escala; ii) ser uma inovação social apropriada para as situações existentes na busca de uma transformação social; iii) e trabalhar com soluções baseadas em projetos objetivos (de justiça social), que exigem uma mudança estrutural (Arond, Thomas \& Abrol, 2012). 
A inovação social, portanto, direciona a necessidade de um foco mais explícito sobre a sustentabilidade (Jaeger-Erben, Rückert-John, \& Schäfer, 2015), envolvendo atividades socialmente inovadoras e seu impacto sobre as relações sociais, patrimônio, cultura, economia e práticas equilíbrio ecológico. Neste sentido, as inovações sociais ajudam a envolver os atores (individual, grupos, comunidades, instituições e governo) com seus objetivos, tais como a mudança climática e esgotamento dos recursos naturais, bem como reforçam a do desenvolvimento sustentável (Mehmood \& Parra, 2013) como um pacto geracional. A inovação social, portanto, pode ajudar a compreender melhor e materializar ações coletivas para promover o desenvolvimento sustentável.

A partir deste entendimento, Mehmood \& Parra (2013) buscaram estabelecer as potenciais relações entre as principais características da inovação social (satisfação das necessidades; mudanças nas relações sociais; capacidade sócio-política; governança e instituições) com as três dimensões do desenvolvimento sustentável (vulnerabilidade social; viabilidade econômica; sustentabilidade ambiental), como apresentado no Quadro 1.
A questão da vulnerabilidade social é tratada nas inovações sociais a partir da satisfação das necessidades básicas e desejos da população, onde são implementadas com base em princípios éticos, o que pode ocorrer por meio de alternativas sustentáveis que sejam social e ambientalmente eficazes. Iniciativas socialmente inovadoras promovem mudanças nas relações sociais e asseguram o envolvimento das partes interessadas através de uma variedade de práticas inclusivas e que promovem o engajamento da comunidade local na busca por meios de satisfazer suas necessidades.

Além disto, considera-se que os movimentos de cidadania são elementos indutores de cooperações, promovendo o diálogo entre os diversos grupos com o propósito de buscar melhorias para as comunidades e potencializar as suas capacidades sócio-políticas. O conceito de governança inserido nestas potenciais relações fornece noções básicas para as diretrizes institucionais, sociais e culturais a que se referem as principais dimensões do desenvolvimento sustentável.

Quadro 1 - Potencial relação entre inovação social e desenvolvimento sustentável

\begin{tabular}{|l|l|l|l|}
\hline $\begin{array}{l}\text { Dimensão do Desenvolvimento } \\
\text { sustentável versus as características da } \\
\text { Inovação social }\end{array}$ & \multicolumn{1}{|c|}{ Vulnerabilidade social } & \multicolumn{1}{|c|}{ Viabilidade econômica } \\
\hline Satisfação das necessidades & $\begin{array}{l}\text { Satisfação básica das } \\
\text { necessidades e desejos; ética }\end{array}$ & $\begin{array}{l}\text { Mitigação das mudanças } \\
\text { climáticas; produção e consumo } \\
\text { sustentável }\end{array}$ & $\begin{array}{l}\text { Biodiversidade; balanço entre as } \\
\text { esferas tecnológicas, ecológicas e } \\
\text { humanas }\end{array}$ \\
\hline Mudanças nas relações sociais & Inclusão social e engajamento & $\begin{array}{l}\text { Comunidades sustentáveis, } \\
\text { empreendedorismo social }\end{array}$ & Transições sócio-ecológica \\
\hline Capacidade sócio-política & $\begin{array}{l}\text { Cooperação; colaboração; } \\
\text { movimentos sociais }\end{array}$ & $\begin{array}{l}\text { Tomada de decisão participativa } \\
\text { Qtimista }\end{array}$ \\
\hline $\begin{array}{l}\text { Governança e instituições } \\
\text { (sociais/culturais) }\end{array}$ & $\begin{array}{l}\text { Identidade; empowerment; } \\
\text { propósito; governança reflexiva }\end{array}$ & $\begin{array}{l}\text { Gestão Adaptativa, iniciativas de } \\
\text { microfinanças investimentos } \\
\text { estratégicos }\end{array}$ & $\begin{array}{l}\text { Regimes de governança flexível e } \\
\text { adaptável }\end{array}$ \\
\hline
\end{tabular}

Fonte: Adaptado de Mehmood e Parra (2013)

Quanto à viabilidade econômica, as inovações sociais buscam satisfazer as necessidades básicas por meio de incentivos às formas de produção e consumo de bens e serviços sustentáveis, além de economicamente viáveis. As iniciativas de empreendedorismo social podem ser uma fonte de economia, com base em sistemas locais de produção que beneficiam não apenas os indivíduos e grupos, mas a comunidade, a sociedade e o meio ambiente. A capacidade sócio-política é estimulada por meio da participação das comunidades no processo de tomada de decisão. Isto inclui o processo de capacitação e de aprendizagem (Benneworth \& Cunha, 2015), envolvendo comunidades locais e atores da sociedade civil, permitindo que tenham a oportunidade de identificar, criar e implementar mecanismos para suprir suas necessidades socioambientais, econômicas e culturais (Dainiené \& Dagiliené, 2015).

No que tange a sustentabilidade ambiental, a inovação social pode se esforçar para encontrar um equilíbrio entre o habitat natural e habitantes humanos, para minimizar os impactos sobre a biodiversidade local. São previstas mudanças nas relações sociais com base em transições sócio ecológicas. A governança e as relações institucionais são vistas como facilitadores da ação social inovadora para o desenvolvimento sustentável e podem ajudar na construção de identidade, reflexividade e autonomia local (Mehmood \& Parra, 2013).

Destarte, as potenciais relações das inovações sociais como iniciativas promotoras do desenvolvimento sustentável ocorrem quando aquelas são materializadas em treinamento e educação; mercado de trabalho, emprego e produção local, ligados a um objetivo de democratizar o desenvolvimento local, por meio da ativação de políticas públicas e atribuindo um papel significativo para as populações locais e os movimentos sociais (MacCallum, 2009; Jaeger-Erben, Rückert-Jonh, \& Schäfer, 2015) em busca do atendimento às necessidades sociais fundamentais da comunidade local. $\mathrm{O}$ empoderamento da população local é o principal fator para que as ações de inovação social promovam o desenvolvimento sustentável.

É evidente que o escopo dos temas inovação social e desenvolvimento sustentável são relacionados, uma vez que os temas envolvem as necessidades políticas, institucionais e sociais e as inovações necessárias para satisfazê-las (Howaldt \& Schwarz, 2010).

O modelo apresentado por Mehmood \& Parra (2013) oferece expressamente possibilidades de se analisar como iniciativas de inovação social se relacionam com a promoção do desenvolvimento sustentável no que se refere a cada uma das suas três principais dimensões, que foi realizado neste estudo através de um estudo de caso. Os procedimentos metodológicos adotados são apresentados na sequência.

\section{Aspectos Metodológicos}

O objetivo deste estudo foi analisar como as iniciativas de inovação social promovidas pelo Centro de Educação Comunitária Rural (CECOR $\mathrm{PE})$, em seus programas de Cisternas (P1MC e P1+2), se relacionam com 
a promoção do desenvolvimento sustentável, através da aplicação do modelo de Mehmood \& Parra (2013). Desta forma, definiu-se que a forma mais adequada para a condução desta pesquisa é o Estudo de Caso que é considerado o método mais apropriado para questões que envolvem o "como" e o "por que" (Yin, 2015).

Os métodos de procedimentos adotados foram o exploratório e descritivo. Exploratório por ter como finalidade proporcionar maiores informações sobre como as iniciativas de inovação social, promovidas pelo Centro de Educação Comunitária Rural (CECOR - PE) em seus programas de Cisternas (P1MC e $\mathrm{P} 1+2)$, se relacionam com a promoção do desenvolvimento sustentável, facilitando a delimitação temática do estudo, uma vez que o tema ainda é pouco explorado. Descritivo, por exprimir características dos programas investigados, delimitando interligações entre os seus aspectos como inovações sociais e as categorias de análise do modelo de Mehmood \& Parra (2013), definindo suas naturezas e implicações.

A unidade de análise deste estudo foi o Centro de Educação Comunitária Rural (CECOR - PE) por ser uma das referências em desenvolvimento e implantação de experiências exitosas voltadas para a convivência com o Semiárido, tendo como base a Agroecologia. A sua atuação se baseia em três eixos: Convivência com o Semiárido, Acesso a Mercado, e Juventude Rural e Gênero. Foram entrevistados 04 (quatro) sujeitos representantes da unidade de análise, distribuídos da seguinte forma: 01 (hum) que atua na Coordenação Executiva (E1), 01 (hum) que trabalha na Assessoria de Comunicação (E2) e 02 (dois) na Assessoria Técnica do CECOR (E3 e E4).

A coleta de dados da pesquisa envolveu dados primários e secundários. As técnicas utilizadas na coleta de dados foram: entrevistas semiestruturadas, análise documental e observação não-participante. Nas entrevistas realizadas, utilizou-se como instrumento de coleta de dados um questionário semiestruturado elaborado a partir do modelo de Mehmood \& Parra (2013). O conteúdo das entrevistas foi gravado com recursos de áudio, além de anotações em caderneta. $A$ análise documental ocorreu a partir de publicações e relatórios que constam informações sobre a organização investigada. Por fim, a observação não-participante ocorreu durante as visitas dos pesquisadores em campo para realização das entrevistas.

Devido à quantidade de informações obtidas, adotou-se como método de análise dos dados a Análise de Conteúdo (Bardin, 2011), para identificar as conexões e categorias existentes nas transcrições das entrevistas realizadas e nos demais documentos analisados que possibilitassem relacionar as características fundamentais das inovações sociais investigadas (satisfação das necessidades humanas; mudança nas relações sociais; capacidade socio-política; e, governança) com as dimensões do desenvolvimento sustentável (vulnerabilidade social; sustentabilidade ambiental; viabilidade econômica), conforme se prevê no modelo de Mehmood \& Parra (2013). Para atender ao critério de rigor científico exigidos para os estudos desta natureza, a análise dos dados seguiu as três etapas do método de análise de conteúdo proposto por Bardin (2011), a saber: pré-análise; exploração do material; e tratamento dos resultados e interpretações. Os resultados encontrados serão analisados em detalhe na próxima seção.

\section{Análise dos Resultados}

Este estudo teve como unidade de análise o CECOR (Centro de Educação Comunitária Rural) que é uma organização social que tem como objetivo incentivar e promover a construção e o fortalecimento de iniciativas de convivência com o semiárido, voltadas para melhorar a vida dos agricultores, tendo como base a agroecologia. Alguns projetos do CECOR são desenvolvidos em parceria com a Articulação do Semiárido (ASA), a saber: O Programa um Milhão de Cisternas (P1MC) que se propõe a instalar um milhão de cisternas para retenção de água para o consumo humano no semiárido brasileiro e o Programa Uma Terra e Duas Águas $(\mathrm{P} 1+2)$, que provê as cisternas de águas para produção de alimentos, possuindo uma meta quantitativa menor que o P1MC por ser de uma complexidade maior. Além desses programas, o CECOR desenvolve outras ações para convivência com o semiárido, considerando como prioridade as questões referentes a segurança alimentar; oferece também intervenção voltada para as ações de acesso ao mercado, assim como o fortalecimento das organizações comunitárias; e um eixo voltado para o empoderamento político e econômico das mulheres e jovens das comunidades e os assentamentos da região (CECOR, 2015).

Para melhor entendimento de como as iniciativas de inovação social, promovidas pelo Centro de Educação Comunitária Rural (CECOR - PE), em seus programas de Cisternas (P1MC e P1+2), se relacionam com a promoção do desenvolvimento sustentável, as subseções seguintes apresentam essas relações a partir do modelo proposto por Mehmood \& Parra (2013).

\subsection{Vulnerabilidade social}

$\mathrm{Na}$ vulnerabilidade social, as necessidades sociais são caracterizadas pela ocorrência de secas prolongadas no semiárido brasileiro, colocando em risco o povoamento e as atividades econômicas no sertão nordestino. A busca por soluções para suprir tais necessidades sociais fez com que acontece um processo de redemocratização, buscando-se alternativas para o desenvolvimento com o semiárido. Assim, algumas organizações da sociedade civil, dentre as quais se insere o CECOR, passaram a formular propostas e realizar projetos com base na ideia de que é possível e necessário conviver com o semiárido (Silva, 2007). Uma das principais iniciativas desenvolvidas envolvem novas tecnologias de captação e armazenamento de água de chuva para consumo humano e para produção de alimentos, as quais geraram novos referenciais para a convivência com a seca.

Neste contexto, ocorreu a formulação de uma ação pública para a região semiárida, que trabalha na perspectiva da formação e mobilização de agricultores para a convivência com o semiárido, a partir dos projetos $\mathrm{P} 1 \mathrm{M}$ e $\mathrm{P} 1+2$ já citados anteriormente. Estes projetos não têm foco no combate aos efeitos da seca, mas, sobretudo, em impor um novo olhar sobre o semiárido, apresentando para a sociedade uma possibilidade de bem-estar mesmo diante das adversidades decorrentes da seca.

Assim, as cisternas construídas nos projetos são consideradas uma inovação social voltada ao processo e resultado, não apenas pelo benefício específico da cisterna, mas por todo o envolvimento do agricultor na implementação dos projetos. Um dos entrevistados enfatiza a importância dos projetos de cisternas ao afirmar que "[...] tenho tido todo esse acompanhamento, e entendido que a cisterna em si é um meio [...]" (E3). A 
fala do representante da Coordenação Executiva entrevistado corrobora a natureza processual da implantação do projeto, o qual se propõe a promover uma transformação social decorrente da emancipação dos agricultores envolvidos, que são capacitados para enfrentar os seus dilemas cotidianos no que tange a falta de água que assola o semiárido brasileiro:

[...] O projeto não consiste de uma doação, mas a partir daquela tecnologia social que foi implementada se trabalha a agricultura familiar de forma geral, trabalha com a assistência técnica e o fortalecimento das organizações dos agricultores [...] na formação deles, para se entender que os agricultores não são agentes passivos, que não sabem de nada e que vão ser formados por nós [...] nós trabalhamos no campo da construção do conhecimento, então, eu costumo fazer reuniões com as famílias e dizer que a cisterna é um brinde, que é apenas um meio de trabalhar a construção do conhecimento junto com as comunidades rurais (E1).

Os projetos $\mathrm{P} 1 \mathrm{MC}$ e $\mathrm{P} 1+2$ não se constituem, portanto, em iniciativas de doação de cisternas, mas em um processo de mobilização das famílias, o que inclui a compreensão da realidade social, econômica, política e ambiental do contexto onde vivem, ou seja, o semiárido, bem como o seu envolvimento e fortalecimento enquanto sociedade civil para o enfrentamento dos problemas sociais que as afligem.

A implantação desses projetos promove mudanças nas relações sociais, a exemplo das experiências de formação dos agricultores e do intercâmbio de experiências bem-sucedidas de manejo de água. Os agricultores que obtiveram êxitos nas suas ações em uma determinada comunidade apresentam-nas em outras localidades, para que haja um momento de troca de experiências e adaptações as suas realidades enquanto agricultores. Surgem, assim, espaços para novos conhecimentos, para a valorização da cultura e do desenvolvimento comunitário local. Nesses espaços, os agricultores têm a oportunidade de conhecer novas realidades, trocar experiências e criar laços solidários entre eles. Dessa forma, os projetos em questão são considerados um meio de trabalhar a construção do conhecimento junto com as comunidades rurais. O propósito é fortalecer a sociedade civil, através da articulação dos agricultores em forma de associações, ampliar a sua participação nas políticas municipais e diminuir do assistencialismo governamental.

Quanto à capacidade sociopolítica, as organizações da sociedade civil parceiras nos programas $\mathrm{P} 1 \mathrm{MC}$ e $\mathrm{P} 1+2$ ganham força a partir do processo de redemocratização da política de convivência com o semiárido, assumindo um papel de difusão de uma nova concepção de desenvolvimento sustentável. O CECOR, ao atuar com o conceito de convivência com o semiárido, propõe-se a utilizar de práticas simples e acessíveis juntos aos agricultores locais, gerando a promoção da qualidade de vida das comunidades em que atuam e a inclusão social. Por isso, considera-se que as inovações sociais implementadas pela unidade de análise desta pesquisa estão relacionadas à promoção do desenvolvimento sustentável, por considerarem a equidade social.

No que tange aos resultados alcançados a partir da implantação dos programas $\mathrm{P} 1 \mathrm{MC}$ e $\mathrm{P} 1+2$, os entrevistados do CECOR concordam que houve empoderamento das comunidades envolvidas nas políticas de convivência com 0 semiárido. Isto resultou em um processo de desenvolvimento de novas formas de organização do trabalho, e de novas práticas sociais que visavam torná-las mais independentes, a partir das melhores conduções de produção e garantia da segurança alimentar. Assim, observou-se que há um discurso institucionalizado no âmbito desses projetos, os quais ecoam como alternativas para efetivação do desenvolvimento do semiárido como um todo e do desenvolvimento local de cada comunidade onde são implantados.

Dentro do enfoque da governança, os formuladores da proposta dos referidos projetos foram as diversas organizações da sociedade civil que atuam no semiárido brasileiro, as quais enfrentam o desafio de influenciar e disputar os processos de formulação de políticas públicas na região, sendo o CECOR uma destas organizações. A Articulação com o Semiárido foi criada com o objetivo de gerar um espaço de articulação política da sociedade civil organizada, tendo como princípios a contribuição para implementação de ações integradas para o semiárido, através da conservação, do uso sustentável e recomposição ambiental dos recursos naturais, a quebra do monopólio do acesso à terra, bem como apoiar a difusão de tecnologias apropriadas que contribuam para a convivência com a seca (Silva, 2007). De acordo com o E2, a ASA é uma rede que não tem personalidade jurídica, trata-se de uma iniciativa que nasceu a partir da trajetória histórica das entidades que a compõem.

Assim, considera-se que os projetos $\mathrm{P} 1 \mathrm{MC}$ e $\mathrm{P} 1+2$ são resultados da ação e articulação entre as organizações da sociedade civil, legitimadas pela atuação da ASA, ao exigirem a formulação de políticas públicas e implantação de ações direcionadas ao atendimento das necessidades emergenciais provocadas pela seca. Impõe, portanto, a implementação de ações estratégicas focadas no desenvolvimento da região que sejam de caráter permanente, o que requer uma maior participação dos agricultores nas políticas municipais e provoca diminuição do assistencialismo governamental. Isto contribui para a diminuição da vulnerabilidade social em nível local.

\subsection{Viabilidade econômica}

Quanto à viabilidade econômica, deve-se enfatizar o processo histórico econômico do homem do campo, refletindo sobre o estado de miséria, da apropriação desigual do espaço, bem como da concentração de renda nas classes dominantes. Assim, a história do semiárido brasileiro é movida pela reprodução das desigualdades. Carvalho (1988) argumenta que os efeitos negativos, de natureza econômica e social atribuídos à seca, não são problemas oriundos exclusivamente desse fenômeno, mas, principalmente, por causa da fragilidade de sua estrutura econômica, politicamente "funcional" à estrutura de poder dominante.

A criação das redes de cooperação, a exemplo da ASA - Articulação com o semiárido,

[...] faz com que se tenha um novo olhar para a realidade do semiárido, saindo da perspectiva de a região é um lugar difícil, onde as pessoas precisam migar porque não tem condições de sobreviver, e apresentando um semiárido com inúmeras possibilidades, de uma riqueza cultural em que o povo agora resiste, experimentando novas formas de convivência com a região (E1).

O programa $\mathrm{P} 1+2$ tem como objetivo armazenar água da chuva para produção de alimentos e garantir a segurança alimentar das famílias agricultoras, fazendo com que as famílias atuem, de forma mais efetiva, na esfera da produção agrícola. A iniciativa investigada proporciona melhoria significativa na renda familiar, através da venda dos produtos cultivados, e possibilita sua participação em representações sociais e em feiras agroecológicas, eliminando o papel do atravessador no processo de comercialização. 
Segundo o coordenador técnico, a CECOR trabalha com apoio às feiras, orientando os agricultores na questão da formação e produção dos alimentos em relação a sua comercialização.

[...] nós trabalhamos no campo da comercialização, de como inserir essas famílias que estão produzindo e como elas podem comercializar seus produtos nas férias agroecológicas, trabalhamos também com 0 apoio à agricultura, junto com a associação de agricultores da região, e nós prestamos assistência técnica ao pessoal, contribuímos nos processos de negociação e comercialização (E3).

As feiras agroecológicas geram maior agregação de valor a produção local, permitindo incrementos expressivos no nível de emprego e renda. "Ela é pensada no âmbito dos quintais produtivos, que tem como objetivo maior, a melhoria da qualidade alimentar e nutricional, e quando ocorre 0 excesso, se trabalha a comercialização" (E2). Dessa forma, os quintais produtivos passaram a ser concebidos como um caminho da redenção regional, com a forma mais eficiente de aproveitamento máximo das vantagens da potencialidade local (Silva, 2007).

Como consequência, acontecem as mudanças nas relações sociais, através do estabelecimento de alternativas de reconfiguração da produção dos agricultores de acordo com a sua realidade, da produção de conhecimentos relativos a uma nova perspectiva agroecológica, e do aproveitamento das potencialidades que o semiárido oferece.

Uma estratégia para fortalecer a capacidade sócio-política, segundo os entrevistados, são os fundos rotativos solidários, orientados pelo interesse de sobrevivência econômica da comunidade, baseados em laços de reciprocidade, que fortalece a sociedade civil no que se refere a sua organização produtiva e inserção a economia mercantil. Os fundos rotativos solidários baseiam-se na cooperação entre os atores envolvidos, a partir de laços sociais de solidariedade, confiança e reciprocidade entre eles (Duque \& Oliveira, 2007). Dessa forma, "os recursos circulam na comunidade, obedecendo sempre a lógica da reciprocidade, que levam os agricultores a compartilharem seus recursos" (E2).

Os fundos rotativos solidários são instrumentos de finanças solidárias (a fundo perdido) direcionadas às comunidades que praticam a auto-gestão desses fundos, formando uma poupança, cuja a própria comunidade decide, em conjunto, quais investimentos serão realizados (Gonçalves, 2010).

Assim, a governança tem foco no processo de modernização econômica, constituindo um novo modelo produtivo (Silva, 2007), pautada na autonomia, correspondendo ao fortalecimento da capacidade de articulação dos atores envolvidos, estimulando a construção do saber local, promovendo a solidariedade e a reciprocidade. A viabilidade econômica consolida-se com a promoção do desenvolvimento local e solidário, destacando a importância da agricultura familiar e sua produção de alimentos para a sociedade.

\subsection{Sustentabilidade ambiental}

A questão ambiental não é considerada apenas uma questão ecológica, mas uma variável interdependente das dimensões econômicas e sociais que refletem uma aproximação entre o meio ambiente e o desenvolvimento, e que envolvem a discussão sobre a necessidade de se promover um manejo sustentável da base de recursos naturais (França \& Oliveira, 2009).

Neste contexto, as ações desenvolvidas pelo CECOR, do ponto de vista da sustentabilidade ambiental, buscam respeitar o meio ambiente, considerando às especificidades de cada região. De acordo com 0 coordenador técnico entrevistado, o CECOR atua com o suporte técnico e o operacional dos projetos $\mathrm{P} 1 \mathrm{MC}$ e $\mathrm{P} 1+2$, ao acompanhar as construções das cisternas nas comunidades. Além disto, o centro oferece programas de capacitação para que os beneficiários possam saber fazer uso eficiente das águas, tanto para consumo humano, como para plantio. Busca-se a ressignificação dos elementos tradicionais que compõem a paisagem do semiárido, a exemplo da algaroba e palma, da dessedentação de animais de pequeno porte e do cultivo da agricultura de subsistência. Desse modo, os técnicos têm a função de apoiar a capacitação dos produtores quanto à promoção do aumento da produtividade dos animais, do suporte forrageiro, além de melhorar o padrão das propriedades e cuidados com a ordenha (Gomes \&Menezes, 2010).

Uma das dificuldades encontradas no processo de capacitação dos agricultores beneficiários para a proteção ambiental é a resistência deles para adoção de novos métodos de trabalho e produção, como cita o coordenador técnico do CECOR:

Teve um técnico que quis ensinar como se trabalha com manejo de caatinga para a produção de lenha, e ele insistindo em convencer o agricultor a usar desse sistema, ai o agricultor respondeu: olhe... na minha roça você não venha com esse negócio de manejo não [...] (E4).

Entretanto, deve-se ressaltar que as capacitações e as experiências de campo servem, principalmente, para orientar o manejo sustentável, estimular os agricultores a respeitar sua realidade, mas também aperfeiçoá-la, identificando os elementos do local e fazendo perceber a importância de se adotar as práticas de proteção ambiental. Segundo o mesmo entrevistado: "[...] se uma família faz uma prática de proteção ambiental é o primeiro sinal que aquela família está percebendo que podem ser protagonista dentro do seu espaço rural" (E4).

Durante a realização das entrevistas verificou-se a disseminação do discurso de que o semiárido não é fruto apenas de desastres, entretanto, com a implementação das tecnologias sociais apropriadas, pode-se alcançar uma mudança na qualidade de vida das comunidades beneficiadas, o que depende do comprometimento delas com a assimilação dos conhecimentos compartilhados. Dentro dos espaços de convivência entre os agricultores, sempre é colocado pontos de reflexão sobre o quanto se tem produzido a mais, como enfatiza um dos entrevistados: "sempre fazemos uma reflexão sobre o que foi plantado, quantos sacos de milhos eles tiravam antes, e hoje? Por que isso aconteceu? E ai o pessoal vai assimilando, vendo a importância de se preservar seu solo" (E1). Este mesmo entrevistado enfatizou que as políticas de convivência com o semiárido estão pautadas no respeito à diversidade cultural e a proteção ambiental, em função da promoção de uma agricultura sustentável e uma produção agroecológica que se posiciona em confronto a produção com agrotóxico, com veneno ou decorrentes de outras práticas inadequadas. Neste contexto, as ações desenvolvidas pelos projetos analisados buscam melhorar a qualidade alimentar das comunidades beneficiadas e despertar seus interesses para práticas ambientais sustentáveis, através da produção de sementes limpas (sem agrotóxicos) e da preocupação com o uso e a proteção do solo.

Nos aspectos referentes à governança inserida nas discussões sobre a sustentabilidade ambiental, percebe-se que a aproximação entre comunidades, poder público e as organizações da sociedade civil, decorrente da implantação dos projetos em análise, permitem a garantia de 
condições mínimas de vida às famílias das comunidades rurais do semiárido que foram beneficiadas, respeitando as especificidades do seu entorno e buscando aproveitar as potencialidades locais, ao mesmo tempo em que se busca promover a proteção ambiental.

Dessa forma, as ações implementadas pelo CECOR e que envolvem os projetos $\mathrm{P} 1 \mathrm{MC}$ e $\mathrm{P} 1+2$ se correlacionam com o paradigma do desenvolvimento sustentável, a partir do momento em que ocorrem mudanças nas concepções e perspectivas de intervenção no semiárido, sendo possível o convívio com a seca, com o fortalecendo do incentivo às atividades econômicas apropriadas, e da melhoria da qualidade de vida das famílias beneficiadas.

\section{Considerações Finais}

O objetivo deste trabalho foi de analisar como iniciativas de inovação social (IS), promovidas pelo Centro de Educação Comunitária Rural (CECOR - PE) em seus programas de Cisternas (P1MC e P1+2), se relacionam com a promoção do desenvolvimento sustentável. E, para tanto, foi utilizado o modelo de Mehmood \& Parra (2013), que se propõe a mapear as conexões que buscam vincular as características fundamentais da inovação social com as dimensões do desenvolvimento sustentável.

O CECOR é uma organização social que tem apoiado a implementação e execução dos projetos sociais, com foco no interesse em oferecer melhor qualidade de vida aos agricultores do semiárido pernambucano, viabilizando a convivência daquela região com os problemas da seca e a inserção de tecnologias sociais como políticas públicas. Nesse sentido, na análise das inovações sociais que envolvem os projetos $\mathrm{P} 1 \mathrm{MC}$ e $\mathrm{P} 1+2$, desenvolvidos pelo centro, foram observadas as três dimensões do desenvolvimento sustentável apresentado no modelo: vulnerabilidade social, viabilidade econômica e sustentabilidade ambiental.

Na vulnerabilidade social, as necessidades sociais são caracterizadas pela implementação das cisternas, o que satisfaz as necessidades de água para o consumo humano e o plantio, além de ampliar o fortalecimento da sociedade civil, através da articulação dos agricultores em forma de associações, com maior participação nas políticas municipais, e da diminuição do assistencialismo governamental. Cada região deve fornecer soluções específicas para seus problemas particulares, apresentando-se como uma reação às soluções generalistas e universais para as quais oferece oportunidades para as sociedades encontrarem suas próprias alternativas para suas demandas sociais (Sachs, 1986).

Quanto à viabilidade econômica, a iniciativa investigada proporciona melhoria significativa na renda familiar, através da venda dos produtos cultivados e possibilita sua participação em representações sociais e em feiras agroecológicas, eliminando o papel do atravessador no processo de comercialização. A prioridade se encontra na geração de trabalho e renda através das alternativas de produção apropriadas às condições climáticas do semiárido. Além de sustentáveis, as iniciativas de produção devem ser inclusivas, com a democratização do acesso aos meios necessários à produção.

No que tange a dimensão de sustentabilidade ambiental, os resultados demonstraram que o foco das iniciativas de inovação social analisadas é melhorar a qualidade alimentar dos agricultores beneficiados, ao mesmo tempo em que desperta seus interesses para práticas de produção sustentáveis, o que inclui o plantio de sementes limpas (sem agrotóxicos) e a preocupação com uso e proteção do solo.

A partir das análises desenvolvidas neste trabalho, foi possível constatar as relações estabelecidas entre as ações desenvolvidas nos projetos $\mathrm{P} 1 \mathrm{Mc}$ e $\mathrm{P} 1+2$, como iniciativas de inovação social, e as dimensões do desenvolvimento sustentável. Pode-se afirmar que as mudanças substanciais nas concepções sobre a realidade e nas proposições para o DS do semiárido expressam modificações profundas nas formas de conceber e explicar a realidade e construir perspectivas futuras (Silva, 2007). Trata-se da implementação de uma prática voltada ao modelo do desenvolvimento sustentável, no qual as intervenções e mudanças ocorrem em nível local, a partir do engajamento e emancipação dos atores sociais, e que tem como meio de promoção a inovação social.

Desse modo, a convivência com o semiárido, a partir de iniciativas sociais como os projetos $\mathrm{P} 1 \mathrm{MC}$ e $\mathrm{P} 1+2$, expressa uma nova perspectiva do desenvolvimento sustentável, que possibilita a satisfação das necessidades fundamentais, como o acesso a água, desenvolvimento de capacidades humanas, distribuição de renda e uso eficiente do solo.

Dessa forma, conclui-se que as características fundamentais das iniciativas de inovação social desenvolvidas pelo CECOR possuem relações mais consolidadas nas dimensões sociais e econômicas do que a dimensão ambiental no escopo do desenvolvimento sustentável. Além disto, foram identificados aspectos que se apresentam de forma mais positiva nesta relação e alguns desafios a serem enfrentados. Sugere-se, portanto, a aplicação do modelo teórico proposto em outros tipos de inovação social para que possam corroborar ou desafiar os resultados obtidos.

\section{Referências}

Abramovay, R. (2012). Muito além da economia verde. Editora Abril.

Arámburo, González \& Rivas. (2017). University vinculación: A two-way strategy for sustainable development and academic relevance, Gateways: International Journal of Community Research and Engagement, vol. 10, pp. 14-32. doi: 10.5130/ijcre.v10i0.5480

Arivumani \& Vijayalaxmi. (2017). Sustainable Development. Advances in Natural and Applied Sciences. 11(7) May 2017, Pages: 296-300.

Around, Thomas \& Abrol. (2012). Grassroots innovation for sustainable development: some enduring dilemmas. Proceedings: Global Research Forum on Sustainable Consumption and Production Workshop, Rio de Janeiro, Brazil.

Bardin, L. (2011). Análise de conteúdo. Porto. Edições 70.

Beck, U. (2011). Sociedade de risco: rumo a uma outra modernidade. Editora 34

Benneworth, P., \& Cunha, J. (2015).Universities' contributions to social innovation: reflections in theory \& practice. European journal of innovation management, 18(4), 508-527.

BEPA - Bureu of European Policy Advisers. (2014). Social Innovation - a decade of changes. Luxembourg: Publications Office of the European Union.

Bittencourt, B. D. L., \& Ronconi, L. F. D. A. (2016). Políticas de inovação social e desenvolvimento: o caso da Bolsa de Terras. Revista de Administração Pública, 50(5) 795-818.

Butkeviciene, E., (2009). Social Innovations in Rural Communities: Methodological Framework and Empirical Evidence. Social Sciences. v. 63, n. 1, p. 80-88.

Cajaiba-Santana, G. (2014). Social innovation: Moving the field forward. A conceptual framework. Technological Forecasting and Social Change, 82, $42-51$.

Caron, A. (2007). Inovação social e o papel da indústria. In: Farfus, D.; Rocha, M. C. S. (Orgs.). Inovações Sociais. Curitiba: SESI/SENAI/IEL/UNINDUS.

Carvalho, O. D. (1988). A economia política do Nordeste. Secas, Irrigação e Desenvolvimento.

CECOR - Centro de Educação Comunitária Rural. Encarte técnico. Disponível em: http://www.cecor.org.br/ Portal Acesso em: 17 de junho de 2015.

Cloutier, J. (2003). Qu'est-ce que l'innovation sociale? Cahier de recherche du CRISES, n. ET0314, Montreal: UQAM.

CMMAD - Comissão Mundial sobre Meio Ambiente e Desenvolvimento. (1991). Nosso futuro comum. 2a ed. Tradução de Our common future. 1a ed. 1988. Rio de Janeiro: Editora da Fundação Getúlio Vargas.

Correia, S. E. N.; Oliveira, V. M., \& Gómez, C. R. P.. Dimensions of social innovation and the roles of organizational actor: the proposition of a framework. RAM, Revista 
Administração Mackenzie (Mackenzie Management Review), v.17, n.6, Special Edition, p. 102-133, Nov/Dec, 2016.

Dainienè, R., \& Dagilienè, L. (2015). A TBL Approach Based Theoretical Framework for Measuring Social Innovations. Procedia-Social and Behavioral Sciences, 213, 275280.

Dearing, A. (2000). Sustainable Innovation: Drivers and Barriers. Innovation and the Environment. OECD: Paris, 103-125.

Dietz, R., \& O'Neill, D. (2013). Enough is enough: Building a sustainable economy in a world of finite resources. Routledge.

Duque, G., \& Oliveira, M. (2007). Comunidade rural e cooperação entre camponeses: os Fundos Rotativos Solidários na Paraíba. In V Congresso Europeu CEISAL de Latino Americanistas, Bruxelas, Bélgica, de (Vol. 11)

Fachinelli, A. C.; D'Arisbo, A.\& Maciel, E. M. (2014) A importância da inovação social e da economia criativa como indutores para o desenvolvimento sustentável. International Journal of Knowledge, Engineering and Management. V. 03, nº 05, p. 276-293.

Farfus, D.\& Rocha, M. C. (2007). Inovação social: Um conceito em construção. In. Farfus, Daniele; Rocha, Maria Cristhina de Souza (orgs.). Inovações sociais. Curitiba: SESI/SENAI/IEL/UNINDUS. (COLEÇÃO INOVA; V. 2).

França, F. M. C.; Oliveira, J. D. L. de. (2009). As estratégias do Banco do Nordeste para o desenvolvimento sustentável do Semiárido regional. In: Simpósio Brasileiro sore Meio Ambiente e desenvolvimento sustentável do semiárido, Mossoró. Anais... Mossoró: UERN.

Furtado, Celso. (2004). Os desafios da nova geração. Revista de Economia Política. Vol. 24, n. 4 (96), pp. 483-486, out. e dez.

Gerometta, J., Haussermann, H., \& Longo, G. (2005). Social innovation and civil society in urban governance: strategies for an inclusive city. Urban Studies, 42(11), 2007-2021.

Goldenberg, M., Kamoji, W., Orton, L \& Williamson, M. (2009). Social Innovation in Canada: An Update. Ottawa: Canadian Policy Research Networks.

Gomes, R. A., \& Meneses, V. F. (2010). As políticas públicas de incentivo a (re) pecuarização no semiárido nordestino: desenvolvimento, modernização e recomposição espacial. In VII Congresso Latinoamericano de Sociologia Rural (ALASRU), Porto de Galinhas-PE.

Gonçalves, A. F. (2010). A História dos fundos rotativos solidários no Estado da Paraíba: A construção político-institucional de uma política pública. Gestão Pública: Práticas e Desafios, 1(1)

Hadden, J., \& Seybert, L. A. (2016). What's in a Norm? Mapping the Norm Definition Process in the Debate on Sustainable Development. Global Governance: A Review of Multilateralism and International Organizations, 22(2), 249-268.

Harris, J. M. (2000). Basic principles of sustainable development. Global Development and Environment Institute, Working Paper n.04, June

Herrera, M. E. B. (2016). Social innovation for bridging societal divides: Process or leader? A qualitative comparative analysis. Journal of Business Research, 69(11), 5241-5247.

Howaldt, J., \& Schwarz, M. (2010). Social Innovation: Concepts, research fields and international trends. K. Henning, \& F. Hees (Eds.).IMA/ZLW.

Hulgård, L., \&Ferrarini, A. V. (2010).Inovação social: rumo a uma mudança experimental na política pública?. Ciências sociais unisinos, 46(3), 256-263.

Jackson, T., \& Senker, P. (2011). Prosperity without growth: Economics for a finite planet. Energy \& Environment, 22(7), 1013-1016.

Jaeger-Erben, M., Rückert-John, J.,\&Schäfer, M. (2015). Sustainable consumption through social innovation: a typology of innovations for sustainable consumption practices. Journal of Cleaner Production, 108, 784-798.

Karampela, S., Papazoglou, C., Kizos, T., \& Spilanis, I. (2017). Sustainable local development on Aegean Islands: a meta-analysis of the literature. Island Studies Journal, 12(1), 71-94.).

Keeys, L. A., \& Huemann, M. (2017). Project benefits co-creation: Shaping sustainable development benefits. International Journal of Project Management.

Koroneos, C. J.,\&Rokos, D. (2012). Sustainable and integrated development-A critical analysis. Sustainability, 4(1), 141-153.

MacCallum, D. (Ed.). (2009). Social innovation and territorial development. Ashgate Publishing, Ltd.
Martin, C. J., Upham, P., \& Budd, L. (2015). Commercial orientation in grassroots social innovation: Insights from the sharing economy. Ecological Economics, 118, 240 251.

Mehmood, A. \& Parra, C. (2013) Social innovation in an unsustainable world. In: Mouleartet. al. The International Handbook in Social Innovation: Collective action, learning and transdisciplinary research. Edward Elgar Publishing, Massachusetts.

Michel, A., \&Hudon, M. (2015). Community currencies and sustainable development: A systematic review. Ecological economics, 116, 160-171.

Mitchell, G. \& Dorling, D. (2003) An environmental justice analysis of British air quality, Environment and Planning A, 35, pp. 909-29.

Moulaert, F. (Ed.). (2013). The international handbook on social innovation: collective action, social learning and transdisciplinary research. Edward Elgar Publishing.

Moulaert, F., Martinelli, F., Swyngedouw, E., \& Gonzalez, S. (2005). Towards alternative model (s) of local innovation. Urban studies, 42(11), 1969-1990.

Mulgan, G., Tucker, S., Ali, R., \& Sanders, B. (2007). Social Innovation: What it is, why it matters and how it can be accelerated, The Young Foundation. Skoll Centre for Social Entrepreneuship Working Paper, 376.

Nicholls, A., \& Murdock, A. (2012). The nature of social innovation. In Social innovation (pp. 1-30). Palgrave Macmillan UK.

Nilsson, W. O. (2003). Social innovation: An exploration of the literature. Bibliography prepared for the McGill Dupont Social Innovation Initiative. McGill University.

Phills, J. A., Deiglmeier, K., \& Miller, D. T. (2008).Rediscovering social innovation. Stanford Social Innovation Review, 6(4), 34-43.

Pisano, U., Lange, L., \& Berger, G. (2015).Social Innovation in Europe. An overview of the concept of social innovation in the context of European initiatives and practices. ESDN Q. Rep, 36, 25.

Pronk, J. \& Hak, M. (1992). Sustainable Development: From Concept to Action. The Hague Report. New York: United Nations Development Program.

Riordan. (1995). Environmental Science for Environmental Management,Longman, London.

Sachs, I. (2007). Rumo à ecossocioeconomia: teoria e prática do desenvolvimento. Cortez.

Sachs, I. (1986). Ecodevelopment: Grow without destroying. São Paulo: Vertex.

Sachs, I. (2004). From poverty trap to inclusive development in LDCs. Economic and Political Weekly, 1802-1811.

Sachs, J. D. (2015). The age of sustainable development. Columbia University Press. Sepúlveda, S., (2008). Biograma: metodología para estimar el nivel de desarrollo sostenible de territorios (No. IICA P01-137). IICA..

Seyfang, G., Longhurst, N. (2013). Growing green money?:mapping community currencies for sustainable development. Ecol. Econ. 86, 65-77.

Silva, R. M. A. D. (2007). Entre o Combate à Seca e a Convivência com o Semi-Árido: políticas públicas e transição paradigmática. Revista Econômica do Nordeste. Fortaleza, 38(3), 466-485.

Soubbotina, T. P. (2004). Beyond Economic Growth: an Introduction to Sustainable Development. The International Bank for Reconstruction and Development/THE WORLD BANK, 2ª Ed., Washington.

Strange, T., Bayley, A., 2008. OECD Insights: Sustainable Development. Linking Economy, Society, Environment. OECD Publishing.

Tardif, C., \& Harrisson, D. (2005). Complémentarité, convergence et transversalité: la conceptualisation de l'innovation sociale au CRISES (No. 513). Crises.

Van Bellen, H. M.(2004) Desenvolvimento Sustentável: uma Descrição das Principais Ferramentas de Avaliação. Ambiente \& Sociedade - V. VII, nº. 1 jan./jun.

Van der Have, R. P., \& Rubalcaba, L. (2016). Social innovation research: An emerging area of innovation studies?. Research Policy, 45(9), 1923-1935.

Veiga, J. E. (2005). Desenvolvimento sustentável: o desafio do século XXI. Editora Garamond.

WCED, 1987

WCED, U. (1987). Our common future. World Commission on Environment and Development Oxford University Press.

Yin, R. K. (2015). Qualitative research from start to finish. Guilford Publications. 